\title{
Particularidades de la transformación de la sociedad cooperativa
}

\author{
José Eduardo de Miranda \\ Director General de Kheíron Educacional y Presidente de la AIDC/BR \\ Ronaldo Gaudio \\ Consultor Jurídico del SESCOOP/RJ y de la AIDC/BR
}

Recibido: 18.06.2013

Aceptado: 30.07.2013

Sumario: Introducción. I. Comprendiendo la transformación societaria. Il. La transformación delante de los demás mecanismos de mutación societaria. III. De la transformación en Sociedad Cooperativa a la transformación de la Sociedad Cooperativa. IV. La señal positiva de la Asamblea General para la transformación de la cooperativa. V. El efecto de la transformación en relación a los miembros. VI. La transformación de la sociedad cooperativa y la preservación de los derechos de los acreedores. VII. El destino de los Fondos en el caso de transformación en el seno de la Sociedad Cooperativa. VIII. La cuestión del capital social en el caso de transformación en sociedad cooperativa. IX. El substrato axiológico-cooperativo como preponderancia de la identidad de la Sociedad transformada en Cooperativa. X. La clasificación de la Sociedad Cooperativa brasileña. XI. Ponderación general respecto a la transformación de la Sociedad Cooperativa brasileña. XII. Escorzo crítico respecto a la transformación de la Sociedad Cooperativa brasileña. XIII. Reflexiones últimas. XIV. Bibliografía.

Resumen: En el presente trabajo aborda las principales cuestiones del instituto de la transformación en el ambiente de la sociedad cooperativa, previstos por la ley de cooperativas de España y por las legislaciones autonómicas de Andalucía, de Valencia y del País Vasco. Asimismo se va a discurrir sobre la transformación en el seno de la ley de cooperativas de Brasil, presentándose un pronunciamiento critico relacionado al silencio del legislador brasileño respecto al tema.

Palabras clave: Transformación; Sociedad Cooperativa; Particularidades.

Abstract: This paper addresses the main issues of the Institute's transformation in the environment of the cooperative society, provided for by the law on cooperatives of Spain and Andalusia, Valencia and the Basque country autonomous community laws. It will also run on the transformation at the heart of the law on cooperatives of Brazil law, presenting a statement related to the silence of the Brazilian lawmaker on the issue critical.

Key words: Transformation; Cooperative society; Special features. 
«La empresa, (que no lo olvidemos) sigue estando al servicio de la sociedad (y no al revés), ha de ser más participativa para ser más social, incrementando la solidaridad con la comunidad a la que se debe.» (Javier Divar) $^{1}$

\section{Introducción}

En el escenario jurídico, las sociedades mercantiles asumen el principal papel como actores ejercientes de las actividades económicas. Por ello, la elección del tipo societario suele realizarse por ocasión de la constitución de la sociedad, cuando los socios optan por la especie jurídica que mejor se ajuste al modelo de negocio, al cumplimiento de los objetivos de la propia actividad y al factor responsabilidad de los miembros del cuadro social².

Ocurre, sin embargo, que independiente del patrón societario elegido en el momento de la constitución de la sociedad, el progreso imparable, la oscilación económica y las diferentes vicisitudes de los socios en el ambiente de una especie societaria suelen provocar situaciones específicas que muy a menudo generan la necesidad de las sociedades mercantiles cambiar su forma jurídica, lo que se muestra posible a través del instituto de la transformación ${ }^{3}$.

En líneas generales, la transformación supone el medio por lo cual una sociedad abandona su vestidura jurídica originaria para adoptar un tipo legal diferente, que a partir de entonces será el que regirá su estructura y funcionamiento ${ }^{4}$. En efecto, la transformación supone el cambio de organización de la sociedad sin la afectación de su personalidad jurídica, -lo que no resulta en el nacimiento de una nueva persona jurídica-, sino que posibilita la modificación de aspectos internos de la sociedad trasformada.

1 DIVAR, Javier. «Poder económico y democracia». In BELTRÁN DE HEREDIA, Pablo J. Ética y actividad empresarial. Madrid: Minerva Ediciones, 2004, p. 29.

2 DIVAR, Javier, GADEA, Enrique y BILBAO, Emilio González. Manual de sociedades anónimas. Madrid: Dykinson, 2000, p. 105.

3 CARVALHO DE MENDONÇA, J. X. Tratado de Direito Comercial Brasileiro. 3. ${ }^{a}$ ed. Rio de Janeiro: Freitas Bastos, 1938, p. 63.

4 IGLESIAS, Juan Luis y GARCÍA DE ENTERRÍA, Javier. «Las modificaciones estructurales de las sociedades», in MENÉDEZ, Aurelio. Lecciones de derecho mercantil. Madrid: Thompson - Civitas, 2003, p. 413. 
Hoy por hoy, en Brasil, la transformación de las sociedades es reglamentada por el Código Civil de 2002 y por la Ley de las Sociedades Anónimas ${ }^{5}$. Dentro del universo legal de regulación de las sociedades brasileñas, el principal hueco reglamentario ocurre en el contexto de las sociedades cooperativas, teniendo en cuenta que, si la transformación no es expresamente prohibida por el legislador, el silencio de la ley provoca inflamados debates sobre su posibilidad, generando posiciones favorables y contrarias.

Por esto, el presente trabajo enfocará la transformación societaria de las sociedades cooperativas a través de un abordaje didáctico.

En el desarrollo del tema, primero se va a presentar algunas consideraciones dogmáticas relacionadas a la transformación, discurriendo sobre su concepto, fundamentación e diferencia del os demás mecanismos de mutación de las sociedades. Después se va a discutir cuestiones generales de la transformación de la sociedad cooperativa, a través de un análisis práctico de la causa-efecto de su ocurrencia. A seguir se va a concentrar en el examen del tema de la transformación en el espacio de la sociedad cooperativa brasileña, explorando, así, los puntos más controvertidos y polémicos de la materia. Luego se ofrece las últimas reflexiones respecto al tema examinado.

\section{Comprendiendo la transformación societaria}

Observase en la praxis que la transformación es un instituto que tiene el propósito de atender a los actuales juicios de conveniencia internos y externos de los socios, que no más se coadunan con aquellos deliberados en el acto de constitución de la sociedad6.

5 Disponible en http://www.planalto.gov.br/ccivil_03/leis/l6404consol.htm y en http://www.planalto.gov.br/ccivil_03/leis/2002/10406.htm.

${ }^{6}$ La transformación depende de la anuencia de los socios, excepto en los casos de previsión contraria en los actos de constitución. En este sentido, el artículo 1.114 del Código Civil brasileño define que «a transformação depende do consentimento de todos os sócios, salvo se prevista no ato constitutivo, caso em que o dissidente poderá retirar-se da sociedade, aplicando-se, no silêncio do estatuto ou do contrato social, o disposto no art. 1.031». Por su vez, el artículo 221 de la Ley de las Sociedades Anónimas brasileñas anuncia que "a transformação exige o consentimento unânime dos sócios ou acionistas, salvo se prevista no estatuto ou no contrato social, caso em que o sócio dissidente terá o direito de retirar-se da sociedade».

(Disponible en http://www.planalto.gov.br/ccivil_03/leis/16404consol.htm y en http:// www.planalto.gov.br/ccivil_03/leis/2002/110406.htm) 
En este sentido, la transformación es la operación por la cual una sociedad pasa, independientemente de disolución o liquidación, de la especie societaria original para otra ${ }^{7}$, a través del cambio del tipo social ${ }^{8}$, con la conservación de la identidad y de la existencia de la persona jurídica9 ${ }^{9}$.

En efecto, la transformación es un proceso metamórfico que convierte la mudanza de la función instrumental de la sociedad ${ }^{10}$, cambiándole las características formales, pero sin la afectación de la persona jurídica. Por así decir, el cambio inducido por la transformación concentrase en la forma societaria, pasando de la elegida en la época de la constitución de la sociedad, para otra, alterándose, entonces, su representación jurídica.

La personalidad jurídica de la sociedad originaria permanece la misma, solamente que bajo "otra forma y contenido jurídico substancialmente diverso cuanto a las relaciones». ${ }^{11}$ Con la transformación, por supuesto, no ocurre disolución, sucesión, extinción o liquidación de la sociedad primitiva para la constitución de otra ${ }^{12}$.

No hay en la transformación societaria, por tanto, de hablarse del nacimiento de otra sociedad, pues la transformación salvaguarda los elementos esenciales innatos a la persona jurídica primitiva, cuáles sean: los socios (todos o algunos), el patrimonio, los créditos, las deudas y la personalidad de la sociedad inicial.

El ocaso se observa exclusivamente en los actos constitutivos originarios, los cuales son sustituidos por otros que ofrecen, a la misma persona jurídica transformada, derechos, obligaciones y responsabilidades diversas en el plan interno, relativas a los socios, e inalteradas en el plan externo, relacionadas a terceros ${ }^{13}$.

7 En BRASIL, el artículo 220 de la Ley de Sociedades Anónimas, Ley 6.404/76, define que "a transformação é a operação pela qual a sociedade passa, independentemente de dissolução e liquidação, de um tipo para outro» (Disponible en http://www. planalto.gov.br/ccivil_03/leis/l6404consol.htm).

8 PONTES DE MIRANDA subraya que "a expressão "transformação da sociedade" tem de ser entendida no sentido de mudança de forma. Muda-se de tipo social» (PONTES DE MIRANDA. Tratado de direito privado. Parte especial. Tomo LI. 3. ${ }^{a}$ ed. São Paulo: Revista dos Tribunais, 1984, p. 59.

9 GIRÓN TENA, J. Derecho de sociedades. TI, Madrid: G.T., 1976, p.352.

10 VIVANTE, apud, TEIXEIRA, Egberto Lacerda. Das sociedades por quotas de responsabilidade limitada. São Paulo: Max Limonad, 1956, p. 288.

11 MODESTO CARVALHOSA. Comentários a lei de sociedades anónimas. V 4, T 1, São Paulo: Saraiva, 1998, p. 177.

12 En BRASIL, el artículo 1.113 de Código Civil dispone que «o ato de transformação independe de dissolução ou liquidação da sociedade, e obedecerá aos preceitos reguladores da constituição e inscrição próprios do tipo em que vai converter-se» (Disponible en http://www.planalto.gov.br/ccivil_03/leis/2002//10406.htm).

13 MODESTO CARVALHOSA, 1998, p. 177. 
La sociedad transformada, de este modo, pasa a desarrollar sus actividades bajo las reglas de existencia y funcionamiento inherentes al nuevo tipo societario adoptado ${ }^{14}$, quedando prohibidas tanto las disposiciones estatutarias incompatibles a la nueva especie como la reminiscencia a las reglas del acto constitutivo original. Los instrumentos que formalizan la transformación deben, así, explicitar

\section{La transformación delante de los demás mecanismos de mutación societaria}

Desde una perspectiva muy amplia, la transformación puede mostrarse semejante a los demás instrumentos que provocan metamorfosis en el seno de las sociedades, como la fusión, la escisión y la incorporación. Ocurre, sin embargo, que, mientras la transformación genera el cambio de la forma y preserva la persona jurídica originaria, la fusión, la escisión y la incorporación conciben el surgimiento una nueva sociedad, de manera que estas no se pueden confundir con aquella.

Bajo una perspectiva económica, la fusión es un fenómeno de concentración de empresas que permite la integración de actividades negociales con el fin de alcanzar una mayor dimensión y adaptarse a las exigencias del mercado. En la legislación brasileña, el artículo 228 de la ley de las sociedades anónimas establece que la fusión es la "operación a través de la cual dos o más sociedades se unen para formar sociedad nueva, sucediendo la otra en derechos y obligaciones» ${ }^{15}$. La fusión, por tanto, determina la extinción de las sociedades que se unen ${ }^{16}$.

Por su vez, la escisión es una operación inversa a la fusión, pues implica una función de reparto o disgregación patrimonial en procesos de reestructuración y descentralización empresarial: en la escisión la sociedad se fragmenta, dividiéndose en dos o más parcelas. En Brasil, se puede constatar por el artículo 229, de la ley de las sociedades anónimas, que la escisión es la maniobra por la cual una sociedad transfiere parcela de su patrimonio para otra, u otras personas jurídicas ${ }^{17}$.

14 El párrafo único del artículo 220, de la Ley de Sociedades Anónimas brasileñas, Ley 6.404/76, establece que "a transformação obedecerá aos preceitos que regulam a constituição e o registro do tipo a ser adotado pela sociedade».

15 Disponible en http://www.planalto.gov.br/ccivil_03/leis/l6404consol.htm.

16 V. Artículo 1.119 de Código Civil brasileño.

(Disponible en http://www.planalto.gov.br/ccivil_03/leis/2002/10406.htm).

17 Disponible en http://www.planalto.gov.br/ccivil_03/leis/l6404consol.htm. 
La incorporación es definida en Brasil por el artículo 1.116 del Código Civil y por el artículo 227 de la ley de las sociedades anónimas como la operación por la cual una o más sociedades son integradas por otra, operándose una sucesión universal de derechos y obligaciones ${ }^{18}$. La incorporación es una operación que atrae para un cuerpo social existente todo lo que deja de existir separadamente ${ }^{19}$.

Visto lo anterior, es posible decirse que los institutos de la fusión, escisión e incorporación tanto inducen a una alteración en el patrimonio societario como generan la afectación de la personalidad jurídica, sea por el nacimiento de una nueva sociedad; sea por la extinción de aquella que ha integrado el negocio jurídico específico. Esto, evidentemente, se muestra absolutamente distinto de la transformación, teniendo en cuenta que aquí el patrimonio y la personalidad jurídica de la sociedad transformada son preservados en su esencia.

\section{De la transformación en Sociedad Cooperativa a la transformación de la Sociedad Cooperativa}

Partiendo del supuesto conceptual de que la transformación es el mecanismo que cambia la forma de la sociedad, preservando su personalidad jurídica originaria, se puede decir que toda persona jurídica libre del aspecto cooperativo puede transformarse en una sociedad cooperativa, siempre que se cumplan las normas de la legislación relativa a la nueva forma societaria, y, así, que los respectivos miembros de aquéllas puedan asumir la posición de cooperadores en relación al objeto social previsto para la entidad resultante de la transformación ${ }^{20}$.

18 Disponible en http://www.planalto.gov.br/ccivil_03/leis/l6404consol.htm y en http://www.planalto.gov.br/ccivil_03/leis/2002/110406.htm

19 Pontes de Miranda, 1984, p. 63.

20 En este sentido dispone el artículo 69.1, de la Ley 27/1999 de Cooperativas de España, que «cualquier asociación o sociedad que no tenga carácter cooperativo y las agrupaciones de interés económico podrán transformarse en una sociedad cooperativa siempre que, en su caso, se cumplan los requisitos de la legislación sectorial y que los respectivos miembros de aquéllas puedan asumir la posición de cooperadores en relación con el objeto social previsto para la entidad resultante de la transformación»; Ley 4/1993, de Cooperativas de Esukadi, artículo 86.1. "Las sociedades y las agrupaciones de carácter no cooperativo podrán transformarse en cooperativas de alguna de las clases reguladas en la presente Ley, siempre que no exista precepto legal que lo prohíba expresamente»; Ley 14/2011, de Cooperativas Andaluzas, artículo 78.5. «Las sociedades y agrupaciones de carácter no cooperativo podrán transformarse en sociedades cooperativas, de conformidad con las disposiciones vigentes, mediante la pertinente inscripción en el Registro de Cooperativas Andaluzas en la forma que reglamentariamente se esta- 
De acuerdo con la orientación de la Ley, la transformación de otro tipo societario en sociedad cooperativa deberá ser formalizada bajo escritura pública que ${ }^{21}$, necesariamente, habrá de contener el acuerdo correspondiente, expresando:

a) La identificación de las personas que ocuparán los cargos del primer Consejo Rector y de interventor, con la respectiva declaración de que no están incursos en causa de incapacidad o prohibición alguna para el desempeño de la función;

b) La declaración de inexistencia de otra entidad con denominación idéntica, a cuyo efecto se presentará el notario la oportuna certificación acreditativa expedida por el Registro de Sociedades; $y$,

c) Los estatutos 22 .

Asimismo, las sociedades cooperativas podrán transformarse en sociedades de cualquier clase y naturaleza, sin que le sea afectada la personalidad jurídica, desde que se verifiquen los requisitos de la legislación especial que en su caso pueda resultar aplicable tanto a la sociedad de origen, como a la sociedad objeto de la transformación ${ }^{23}$.

Además, hay que destacar el caso específico de la ley de cooperativas de España, que prevé la posibilidad de las cooperativas de segundo grado transformarse en cooperativas de primer grado, quedando absorbidas las cooperativas socios. Es importante señalar que las cooperativas socios, y también los socios de éstas, disonantes con los pactos de transformación y absorción, podrán apartarse mediante escrito dirigido al Consejo Rector de las cooperativas de segundo grado o primer grado, según proceda, en el plazo de un mes contado a partir de la fecha de publicación del anuncio de transformación y absorción ${ }^{24}$.

blezca»; Ley 8/2003, de Cooperativas de la Comunidad Valenciana, artículo 80.1 «Las sociedades y las agrupaciones de carácter no cooperativo podrán transformarse en cooperativas de alguna de las clases reguladas en la presente ley, siempre que no exista precepto legal que lo prohíba expresamente».

21 En la escritura se podrán incluir todos los pactos y condiciones que los promotores juzguen conveniente establecer, siempre que no se opongan a las leyes ni contradigan los principios configuradores de la sociedad cooperativa.

22 Ley 27/1999 de Cooperativas de España, artículo 10 y artículo 69.3.

23 Ley 27/1999, de Cooperativas de España, artículo 69.1 «Asimismo, las sociedades cooperativas podrán transformarse en sociedades civiles o mercantiles de cualquier clase. En ningún caso se verá afectada la personalidad jurídica de la entidad transformada».

24 Artículo 77.5, de la Ley 27/1999 de Cooperativas, en España 


\section{La señal positiva de la Asamblea General para la transformación de la cooperativa}

Ya queda muy claro que la transformación se muestra como una reforma en la estructura de la sociedad que debe ser ratificada unánimemente por su seno vital: sus miembros ${ }^{25}$.

La trasformación de la sociedad cooperativa necesariamente ha de producirse a través de la existencia de acuerdo expreso y favorable de la Asamblea General, que es el órgano que tiene competencia exclusiva para amparar los acuerdos que provocan modificaciones estructurales de la sociedad ${ }^{26}$.

\section{El efecto de la transformación en relación a los miembros}

La transformación de la sociedad cooperativa en otro tipo societario aflige la figura del miembro, que tiene su posición afectada en aspectos muy propios, como en relación al régimen de responsabilidad, sus derechos y obligaciones, e, incluso, la valoración del interés económico de su participación. Por ello, en el desarrollo del proceso de transformación, los socios contrarios al cambio del tipo societario tienen garantizado el derecho de separación, y, con ello, el derecho al reembolso de sus aportaciones al capital, de acuerdo con el régimen establecido por cada una de las legislaciones ${ }^{27}$.

Sin embargo, la participación de los socios de la cooperativa en el capital social de la sociedad resultante de la transformación será proporcional al que tenían en aquélla. No obstante, el acuerdo de transformación en algún tipo de entidad de cuyas deudas respondan personalmente los socios, tan sólo surtirá efectos respecto de los que hayan votado a favor del acuerdo, una vez que el socio contrario tiene derecho a la separación y a la restitución de sus respectivas aportaciones de capital28.

25 Véase anotación de la referencia 9.

26 V. artículo 79.1, a, de la Ley 8/2003, de Cooperativas de la Comunidad Valenciana; artículo 69.2, de La Ley 27/1999, de Cooperativas de España; artículos 74 y 78 , de la Ley 14/2011, de las Cooperativas Andaluzas; artículo 85.1, b, de la Ley 4/1993, de las Cooperativas de Euskadi.

27 Artículo 85.3, de la Ley 4/1993, de Cooperativas de Euskadi; artículo 78.3 y 23, de la Ley14/2011, de las Cooperativas Andaluzas; artículo 69,2, de la Ley 27/1999, de Cooperativas de España; y artículo 79.4, de la Ley 8/2003, de Cooperativas de la Comunidad Valenciana.

28 V. artículo 69.2, de la Ley 27/1999, de las Cooperativas de España. 
En la medida que alcanza los intereses económicos de los miembros, la transformación también puede afectar a su régimen de responsabilidad en el caso de trasformación de cooperativa en un tipo societario en que los miembros tengan responsabilidades personales ilimitadas por las deudas sociales, o de la trasformación de una sociedad en la que los socios respondan personal e limitadamente por las deudas sociales, en cooperativa.

Para los casos de transformación de otra sociedad en cooperativa, la responsabilidad personal de los socios, por las deudas sociales contraídas antes del acuerdo no se ve afectada, salvo consentimiento expreso a la transformación por los acreedores ${ }^{29}$.

Del mismo modo, los socios que en virtud de la transformación pasen a responder personalmente por las deudas sociales, responderán de igual forma por las deudas anteriores de la sociedad cooperativa ${ }^{30}$.

\section{La transformación de la sociedad cooperativa y la preservación de los derechos de los acreedores}

Una vez que la transformación no extingue la persona jurídica, y, también, no exonera a los socios de la responsabilidad personal por las deudas tomadas antes del acuerdo, el acreedor, además de ver preservadas sus garantías originales, solo tiene su condición modificada si así lo admite expresamente ${ }^{31}$.

No obstante, hay que anotar que en las Leyes que han sostenido el análisis, no hay cualquier dispositivo que ofrezca a los acreedores un derecho de oposición, por escrito, a la transformación, impidiendo que la misma se opere antes de la satisfacción integral de sus créditos ${ }^{32}$.

\section{El destino de los Fondos en el caso de transformación en el seno de la Sociedad Cooperativa}

En los casos de transformación de sociedad cooperativa en otra sociedad, de cualquier clase o naturaleza, el destino de los fondos de

29 V. artículo 69.5, de la Ley 27/1999, de las Cooperativas de España.

30 Ibid.

31 Artículo 80.4, de la Ley 4/1993 de Cooperativas de Euskadi y artículo 69.5, de la Ley 27/1999, de Cooperativas de España.

32 Conforme el artículo 66, de la Ley 27/1999. 
reserva obligatorio, el fondo de educación y cualquier otro fondo o reservas que estatutariamente no sean repartibles entre los socios, recibirán el destino previsto para el caso de liquidación de la cooperativa.

De este modo, «el importe del fondo de educación y promoción se pondrá a disposición de la entidad federativa a la que esté asociada la cooperativa. Si no lo estuviere, la Asamblea General podrá designar a qué entidad federativa se destinará»33.

Por otro lado, en la hipótesis de no producirse designación, dicho importe será repasado de acuerdo con la determinación de la legislación autonómica específica, o, según la Ley 27/1999, será transferido a la Confederación Estatal de Cooperativas de la clase correspondiente a la cooperativa transformada y, en no existiendo la Confederación correspondiente, se ingresará en el Tesoro Público con la finalidad de destinarlo a la constitución de un Fondo para la Promoción del Cooperativismo ${ }^{34}$.

\section{La cuestión del capital social en el caso de transformación en sociedad cooperativa}

Las características, organización y función del capital son modulables de acuerdo a la voluntad de los miembros, a través de la Asamblea General, por cuenta de su aspecto instrumental, propio a la distinción de los tipos sociales en transformación. El capital social, así, es un elemento estructural que precisa ser ecualizado de una forma societaria a otra, conformando las exigencias del nuevo tipo societario o a las exigencias de la sociedad y a los intereses de los socios.

Importante subrayar que capital y patrimonio tienen la función definida por los miembros. Para la trasformación en cooperativa, por tanto, necesario atención para las reglas de los artículos 24 y 42 de la Ley 5.764/1971, de cooperativas brasileñas, los cuales establecen como fundamental:

a) Tornar el capital un instrumento de viabilidad del emprendimiento, mitigando el aspecto especulativo antecedente;

b) Distribuir el excedente no como forma de remuneración del capital o en función del capital, pasando a la división de los resultados en razón de las operaciones con los socios;

33 Artículos 69.6 y 75.2, de la Ley 27/1999.

34 Artículo 75.2, de la Ley 27/1999. 
c) Suprimir el poder de deliberación del capital, tornándole indiferente para esta finalidad, en virtud del prestigio a la regla de un voto por individuo;

d) Respetar el límite máximo de titularidad sobre 1/3 del capital por socio.

La voluntad que ofrece y organiza el capital en el acto de constitución de la sociedad cooperativa, es voluntad igual a que se manifiesta en el momento de transformación, y, así, esta voluntad posee las condiciones propias para la readecuación del capital a las características de la sociedad transformada, ajustándole en función de las aportaciones de los miembros y definiéndole en razón de las posibilidad y disponibilidad de los mismos.

\section{El substrato axiológico-cooperativo como preponderancia de la identidad de la Sociedad transformada en Cooperativa}

Una vez permitida la transformación de las sociedades o de las agrupaciones de carácter no cooperativo en cualquier de las clases de cooperativas reguladas por Ley, es importante subrayar que el Cooperativismo constituye una doctrina que comprende el conjunto del conocimiento profundo derivado de experiencias teóricas y prácticas que a lo largo del tiempo han sido perfeccionadas en base a las costumbres y saberes acumulados ${ }^{35}$; y, "por su vez, la sociedad cooperativa encuentra su lugar a tono con su peculiar naturaleza, cuando determinado el marco genérico que la reconoce como entidad fundada en el esfuerzo propio y la ayuda mutua para organizar y prestar servicios, reúne determinados caracteres particulares que completan su perfil jurídico» 36 .

Por así decir, la persona humana es la principal característica que sirve para distinguir la sociedad cooperativa de cualquier otra empresa organizada en beneficio del capital. En las cooperativas, los socios tienen derechos de una amplitud interesante: son derechos de intervención, de ser informados, de estar involucrados y derechos de participar en la toma de decisiones ${ }^{37}$.

35 MIRANDA apud MÖLLER «la cooperación no se basa en una nueva teoría de la conducta humana, sino en el desenvolvimiento de las tendencias históricas de la humanidad que ella trata de fortificar en el presente como porvenir» (MÖLLER, E. Doctrina histórica del cooperativismo. Cooperativismo como proceso de cambio. La Paz: Editorial los Amigos del Libro, 1986, p. 39).

36 MIRANDA, José Eduardo de. De la crisis de identidad al rescate de la génesis del cooperativismo. Dykinson: Madrid, 2012, p. 18.

37 MIRANDA, 2012, p. 90. 
La sociedad cooperativa siempre ha constituido un medio de intervención, un instrumento de realización del derecho de participación del ciudadano en la vida económica, social y cultural del país. La forma en que se articula la sociedad cooperativa la hace, en sentido técnico jurídico, una entidad basada en la participación personal de sus socios ${ }^{38}$, una participación para el éxito de la entidad, y, sobre todo, para el desarrollo del entorno donde se encuentre inserida la cooperativa.

Por ello, toda la entidad que se transforme en cooperativa debe comprender que «la principal tarea de la entidad cooperativa es sembrar el entendimiento entre los ciudadanos; ubicar su ejercicio empresarial en el sentido más ventajoso al bien común; favorecer la solución de las dificultades, permitiendo nuevos caminos que conduzcan a los individuos al encuentro de la prosperidad; y participar del desarrollo educativo del ser humano, de forma que éste se vea involucrado en una existencia basada en la labor coparticipativa» ${ }^{39}$.

\section{La clasificación de la Sociedad Cooperativa brasileña}

En Brasil, el Código Civil de 2002 adoptó la teoría de los actos de la empresa y estableció, por el artículo 966, que el empresario es aquel que ejerce profesionalmente una actividad económica propia para la circulación de productos o servicios ${ }^{40}$.

No obstante conectar el fenómeno de la circulación de productos o servicios a la figura del empresario, el legislador brasileño quitó de la sociedad cooperativa esta condición, pues, a través el artículo 982, el

38 Rosembuj nos recuerda que la cooperativa «no es un instrumento de activación de una preexistente categoría sociológica. Si bien no puede dejar de aceptarse que la cooperativa, como «hija de la necesidad» que es, satisface, por lo regular, a los sectores económicos menos dotados de la comunidad; no es menos cierto, que su configuración jurídica establece la relación asociativa y los respectivos derechos y obligaciones entre los que participan en la entidad, su socios. Los que se adhieren a una cooperativa no persiguen intereses de categoría o clase, aunque pudieran hacerlo, sino un propio interés económico, cultural, social. La cooperativa es de y para los que la trabajan» (ROSEMBUJ, T. La empresa cooperativa. Barcelona: CEAC, 1982, p. 10).

39 MIRANDA, 2012, p. 78 y 83.

40 En este sentido, el artículo 966, del Código Civil brasileño dispone: «Art. 966. Considera-se empresário quem exerce profissionalmente atividade econômica organizada para a produção ou a circulação de bens ou de serviços. Parágrafo único. Não se considera empresário quem exerce profissão intelectual, de natureza científica, literária ou artística, ainda com o concurso de auxiliares ou colaboradores, salvo se o exercício da profissão constituir elemento de empresa (BRASIL. Código civil. 55 ed. São Paulo: Saraiva, 2004, p. 193) 
Código Civil brasileño determina que se considera empresaria la sociedad que tiene por objeto el ejercicio de la actividad propia de empresario sujeto a registro, y simple las demás. De manera complementar, el párrafo único del artículo 982 establece que independiente de su objeto, se considera empresaria la sociedad por acciones, y simple la cooperativa ${ }^{41}$.

Independiente del análisis del objeto y de la dinámica del ejercicio de su actividad42, el legislador brasileño suprimió la calidad empresarial de la sociedad cooperativa, atribuyéndole la naturaleza de simple, propia de las sociedades que tienen por objeto el desarrollo de actividades rurales o intelectuales, de naturaleza científica, literaria o artística.

De otra forma, es importante decir que el artículo 981, del Código Civil brasileño, establece que el contrato de sociedad es celebrado por aquellos que se obligan contribuir con bienes o servicios para el desarrollo de actividades económicas y división del provecho entre sí43.

En este sentido, hay que subrayar que el ejercicio de la actividad económica es objeto de la sociedad cooperativa brasileña; y que la división de los resultados es una característica también esencial que encuentra perfecta harmonía con la previsión del artículo 981. La diferencia de la cooperativa para la sociedad empresaria es la finalidad (su objetivo), pues, mientras la sociedad cooperativa persigue una prestación de servicios de soporte a la operación económica de los miembros, para fortalecer sus condiciones socioeconómicas, las sociedades de apariencia capitalista buscan exclusivamente la distribución del lucro 44 .

A par de ello, es importante decir que la Ley brasileña, cuando quita de la cooperativa el aspecto empresarial, se opone a la definición global de sociedad cooperativa, comprendida como una asociación de

41 «Art. 982. Salvo as exceções expressas, considera-se empresária a sociedade que tem por objeto o exercício de atividade própria de empresário sujeito a registro (art. 967); e, simples, as demais. Parágrafo único. Independentemente de seu objeto, considera-se empresária a sociedade por ações; e, simples, a cooperativa. (BRASIL. Código civil. 55 ed. São Paulo: Saraiva, 2004. p. 195).

42 BORBA, José Edwaldo Tavares. Direito Societário. 8. ${ }^{a}$ ed., Rio de Janeiro: Renovar, 2003; y CAMPINHO, Sergio. O Direito da Empresa à Luz do novo Código Civil. 3. ${ }^{a}$ ed., Rio de Janeiro, Renovar, 2003.

43 Código Civil, Artículo 981: «Celebram contrato de sociedade as pessoas que reciprocamente se obrigam a contribuir, com bens ou serviços, para o exercício de atividade econômica e a partilha, entre si, dos resultados. Parágrafo único. A atividade pode restringir-se à realização de um ou mais negócios determinados».

44 FRANK, Walmor. Direito das Sociedades Cooperativas. São Paulo: Ed. Da Universidade de São Paulo, 1973, p. 37. 
personas que se unen de forma voluntaria para satisfacer sus necesidades y aspiraciones económicas, sociales y culturales en común, mediante una empresa de propiedad conjunta y de gestión democrática ${ }^{45}$.

\section{Ponderación general respecto a la transformación de la Sociedad Cooperativa brasileña}

La Ley 5.764/71, de Cooperativas brasileñas, omite norma relacionada a la transformación como posibilidad de cambio de la forma societaria, o del tipo de sociedad, mediante la preservación de la individualidad y de la personalidad jurídica de la sociedad originaria.

Relativamente a las modificaciones estructurales del estatuto, la Ley de cooperativas brasileñas prevé solamente la posibilidad de fusión, de incorporación y de desmembramiento, fenómenos muy distintos de la transformación abordada por el presente trabajo, teniendo en cuenta que estos últimos provocan la extinción de una sociedad o el nacimiento de otra.

En este sentido, el artículo 57, de la Ley 5.764/71, establece que, por la fusión, dos o más cooperativas forman nueva sociedad ${ }^{46}$, mientras que el artículo 58 prescribe que la fusión determina la extinción de las sociedades que se unen para formar una nueva, que le sucederá en derechos y obligaciones ${ }^{47}$. Aquí, diferente de la transformación, tanto hay el surgimiento de una nueva sociedad, como la extinción de las sociedades que operan en el negocio jurídico.

La incorporación, a su vez, es contraria a la fusión pues trata de la agregación al patrimonio y cuadro social de una sociedad cooperativa del patrimonio y miembros de otra entidad. Según establece el artículo 59 de la Ley brasileña 5.764/71, la sociedad cooperativa que incorpora asume las obligaciones y se inviste en los derechos de otra o de otras, que, incorporadas dejan de existir en el mundo del derecho, extinguiéndose ${ }^{48}$.

45 ICA. Declaración de la Alianza Cooperativa Internacional sobre la Identidad Cooperativa, in Instituto de Estudios Cooperativos. Anuario de estudios cooperativos. Bilbao: Universidad de Deusto, 1995, p. 73.

46 Ley 5.764/71: «Art. 57. Pela fusão, duas ou mais cooperativas formam nova sociedade.»

47 Ley 5.764/71: "Art. 58. A fusão determina a extinção das sociedades que se unem para formar a nova sociedade que lhe sucederá nos direitos e obrigações.»

48 Ley 5.764/71: Art. 59. Pela incorporação, uma sociedade cooperativa absorve o patrimônio, recebe os associados, assume as obrigações e se investe nos direitos de outra ou outras cooperativas.» 
Por fin, en Brasil, el artículo 60 de la Ley de cooperativas dispone de un instituto muy similar a la escisión, que es la desmembración. Mecanismo que posibilita la división de una sociedad, la desmembración materializase por la transferencia del patrimonio de una sociedad para otra u otras, extinguiéndose aquella que transfiere para el nacimiento de las demás, las cuales pueden, incluso, ser constituidas como cooperativas centrales o federaciones de cooperativas. ${ }^{49}$

Ya resulta evidente que la fusión, la escisión y la desmembración previstas por la Ley de cooperativas brasileña no reflejan transformación societaria, como fenómeno de cambio del tipo y de preservación de la identidad de sociedad originaria y de su personalidad jurídica.

Es por ello que, hoy por hoy, el proceso de mutación de la forma o de tipo societario, en el ámbito de las sociedades cooperativas brasileñas, no se establece bajo las características del proceso de transformación, pues en la hipótesis de búsqueda por un nuevo tipo societario este suele derivar, primero, de la constitución de la sociedad cooperativa, con la consecuente extinción de la persona jurídica originaria, en la mayoría de las veces asociaciones, que son entidades jurídicas colectivas constituidas para el desarrollo de actividades no económicas.

\section{Escorzo crítico respecto a la transformación de la Sociedad Cooperativa brasileña}

La ocultación de reglamento específico para la transformación, en el seno de la Ley de cooperativas brasileñas no es motivo para que la misma no pueda ser utilizada como alternativa de modificación de forma o tipo societario, muchas de las veces necesaria al ajuste de la persona jurídica a las demandas del mercado.

No hay ninguna incompatibilidad que impida que la sociedad de personas se torne una sociedad de capital, o de otra forma, la de capital cambie a una sociedad de personas. Mismo que las características, funciones y organización del capital se muestren diferentes entre ellas, hay que observarse que el arreglo en el nuevo tipo depende solamente de la voluntad de los socios, de la misma forma que ha ocurrido originariamente, cuando de la constitución de la sociedad.

49 Ley 5.764/71: Art. 60. As sociedades cooperativas poderão desmembrar-se em tantas quantas forem necessárias para atender aos interesses dos seus associados, podendo uma das novas entidades ser constituída como cooperativa central ou federação de cooperativas, cujas autorizações de funcionamento e os arquivamentos serão requeridos conforme o disposto nos artigos 17 e seguintes. 
Además, dentro del régimen jurídico de la actividad económica privada, la ausencia o la superficial manifestación de la Ley, respecto a la transformación, significa solamente que la misma no está reglamentada, pero esto no implica decir que está prohibida. La transformación está, entonces, entregue a la voluntad de los miembros, y por cuenta de esto debe materializarse sin ningún impedimento.

La materia de la transformación de la sociedad cooperativa brasileña queda, por tanto, bajo la voluntad de los socios y a merced de la exégesis de la doctrina y de los jueces, de cuya interpretación salen posicionamientos que modifican el obstáculo impuesto por la Ley y abren los caminos para que, después de afectarse la cooperativa con el aspecto de la empresarialidad, pueda ella sufrir la metamorfosis que se muestre necesaria a su adecuación a las demandas del mercado o a los interese de sus miembros ${ }^{50}$.

\section{Reflexiones últimas}

Actualmente, la transformación societaria se muestra importante instituto, utilizado para eventuales ajustes estructurales de interese de los socios en el ambiente de las diferentes personas jurídicas, provocándose la mutación de la forma o del tipo societario sin afectarse la identidad o la personalidad de la sociedad originariamente constituida.

En el ambiente de la sociedad cooperativa, la legislación de cooperativa de España, y de las comunidades de Andalucía, Valencia e País Vasco reúne los elementos adecuados a la promoción del fenómeno transformativo, sin la necesidad de extinción de la cooperativa, para, entonces, constituirse otra persona jurídica.

50 ADMINISTRATIVO. MANDADO DE SEGURANÇA. TRANSFORMAÇÃO DE COOPERATIVA EM SOCIEDADE LIMITADA. ALTERAÇÃO DA RAZÃO SOCIAL NO CNPJ. INDEFERIMENTO PELA DELEGACIA DA RECEITA FEDERAL. EXIGÊNCIA ILEGAL DE LIQUIDAÇÃO DA COOPERATIVA. SEGURANÇA CONCEDIDA. 1. Está configurada a ilegalidade do cancelamento do CNPJ provisório da impetrante, porque não é exigível a liquidação da cooperativa para caracterizar sua dissolução, uma vez que o inciso IV do art. 63 da Lei 5.764/71, que rege as Cooperativas, dispõe que as sociedades cooperativas se dissolvem de pleno direito "devido à alteração de sua forma jurídica», sendo essa a hipótese dos autos, em que houve transformação da cooperativa em sociedade limitada. A segurança deve ser concedida para assegurar à impetrante o direito de manutenção do mesmo número de cadastro no CNPJ e para seja dado andamento ao pedido de alteração da razão social. 2. Dá-se provimento ao recurso de apelação. (AMS 2002.38.00.053878-8 / MG; APELAÇÃO EM MANDADO DE SEGURANÇA - JUIZ FEDERAL RODRIGO NAVARRO DE OLIVEIRA / 4. ${ }^{a}$ TURMA SUPLEMENTAR - 15/05/2013 e-DJF1 p. 354) 
Puede decirse que dichas legislaciones presentan un verdadero avance en relación a Brasil, puesto que la ley brasileña de cooperativas omite cualquier indicación respecto al tema. Los únicos institutos previstos por la ley de cooperativas brasileñas para el cambio de la forma societaria son la fusión, la incorporación y la desmembración, pero todos muy distintos de la transformación, una vez que su ocurrencia siempre va a generar la extinción o la creación de una o de otras sociedades.

El hecho de la Ley brasileña omitir la posibilidad de transformación en el ambiente de la sociedad cooperativa no implica en prohibición, sino que su ocurrencia debe realizarse de acuerdo con la voluntad de los miembros, sin que los mismos encuentren impedimentos para tal. El cambio de la forma o del tipo societario es un elemento que interesa a los socios y es justamente ellos que deben decidir cuál es la mejor especia de sociedad que atienda las nuevas demandas del mercado, y, así, satisfaga a sus intereses.

Vetar la transformación, determinándose la extinción de la sociedad para que los socios puedan constituir otra, bajo la forma que les interesa, redunda en una burocracia indebida que incrementa aún más el coste de la actividad económica, implicando en verdadera ineficiencia y obstáculo al desarrollo económico, lo que ocurre con el tiempo que se pierde con la salida de la sociedad del mercado y con todo el aparato burocrático que se debe cumplir para la constitución de la nueva sociedad.

\section{Bibliografía}

BORBA, José Edwaldo Tavares. Direito Societário. 8. a ed., Rio de Janeiro: Renovar, 2003.

BRASIL. Código civil. 55 ed. São Paulo: Saraiva, 2004.

CAMPINHO, Sergio. O Direito da Empresa à Luz do novo Código Civil. 3. ${ }^{a}$ ed., Rio de Janeiro, Renovar, 2003.

CARVALHO DE MENDONÇA, J. X. Tratado de Direito Comercial Brasileiro. 3. ${ }^{\text {a }}$ ed. Rio de Janeiro: Freitas Bastos, 1938.

DIVAR, Javier. Poder económico y democracia. In BELTRÁN DE HEREDIA, Pablo J. Ética y actividad empresarial. Madrid: Minerva Ediciones, 2004.

DIVAR, Javier, GADEA, Enrique e BILBAO, Emilio González. Manual de sociedades anónimas. Madrid: Dykinson, 2000.

FRANK, Walmor. Direito das Sociedades Cooperativas. São Paulo: Ed. Da Universidade de São Paulo, 1973.

GIRÓN TENA, J. Derecho de sociedades. TI, Madrid: G.T., 1976.

ICA. Declaración de la Alianza Cooperativa Internacional sobre la Identidad Cooperativa, in INSTITUTO DE ESTUDIOS COOPERATIVOS. Anuario de estudios cooperativos. Bilbao: Universidad de Deusto, 1995 
IGLESIAS, Juan Luis y GARCÍA DE ENTERRÍA, Javier. Las modificaciones estructurales de las sociedades, in MENÉDEZ, Aurelio. Lecciones de derecho mercantil. Madrid: Thompson - Civitas, 2003.

MIRANDA, José Eduardo de. De la crisis de identidad al rescate de la génesis del cooperativismo. Madrid: Dykinson, 2012.

MÖLLER, E. Doctrina histórica del cooperativismo. Cooperativismo como proceso de cambio. La Paz: Editorial los Amigos del Libro, 1986.

MODESTO CARVALHOSA. Comentários a lei de sociedades anónimas. V 4, T 1, São Paulo: Saraiva, 1998.

PONTES DE MIRANDA. Tratado de direito privado. Parte especial. Tomo LI. 3. ${ }^{a}$ ed. São Paulo: Revista dos Tribunais, 1984.

ROSEMBUJ, T. La empresa cooperativa. Barcelona: CEAC, 1982

TEIXEIRA, Egberto Lacerda. Das sociedades por quotas de responsabilidade limitada. São Paulo: Max Limonad, 1956.

VIVANTE, apud, TEIXEIRA, Egberto Lacerda. Das sociedades por quotas de responsabilidade limitada. São Paulo: Max Limonad, 1997.

Legislación

Ley 27/1999, de 16 de julio, de Cooperativas. Disponible en http://noticias.juridicas.com/base_datos/Privado/l27-1999.html

Ley 4/1993, de 24 de junio, de Cooperativas de Euskadi. Disponible en http:// www.euskadi.net/cgiin_k54/ver_c?CMD=VERDOC\&BASE=B03J\&DOCN=0 00008829\&CONF=bopv_c.cnf

Ley 14/2011, de 23 de diciembre, de Cooperativas Andaluzas. Disponible en http://www.boe.es/diario_boe/txt.php?id=BOE-A-2012-877

Ley 8/2003, de 24 de marzo, de Cooperativas de la Comunidad Valenciana. Disponible en http://noticias.juridicas.com/base_datos/CCAA/va-l8-2003. html

Ley 6.404/76, de 15 de dezembro, de Sociedades Anônimas. Disponible en http://www.planalto.gov.br/ccivil_03/leis/l6404consol.htm.

Ley 10.406/202, de 10 de janeiro de 2002. Disponible en http://www. planalto. gov.br/ccivil_03/leis/2002/10406.htm 